\title{
The bactericidal activity of various aminoglycoside antibiotics against Mycobacterium leprae in mice
}

\author{
R H GELBER*, P R HENIKA $†$ \& J B GIBSON $\ddagger$ \\ US Public Health Service Hospital, 15th Avenue and Lake Street, \\ San Francisco, California 94118, USA
}

Accepted for publication 22 March 1984

\begin{abstract}
Summary The killing potential of various aminoglycoside antibiotics for $M y c o-$ bacterium leprae infection of the mouse foot-pad was studied, utilizing daily intraperitoneal therapy. Kanamycin $(100 \mathrm{mg} / \mathrm{kg})$, streptomycin $(150 \mathrm{mg} / \mathrm{kg})$, and amikacin $(100 \mathrm{mg} / \mathrm{kg})$ resulted in impressive killing of bacilli $(99.7 \%, 97 \%$ and $96 \%$ bactericidal, respectively). Gentamicin $(20 \mathrm{mg} / \mathrm{kg})$ and tobramycin $(20 \mathrm{mg} / \mathrm{kg})$ were much less active $(60 \%$ and $37 \%$ bactericidal). The bactericidal activity of these very high doses of kanamycin, streptomycin and amikacin compared favourably with those of other agents previously studied in a similar manner at relatively lower dosage levels.
\end{abstract}

\section{Introduction}

Aminoglycoside antibiotics have received only limited experimental and/or clinical attention for their potential role in the therapy of leprosy. ${ }^{1-9}$ In 1964 the first study ${ }^{8}$ on the activity of streptomycin in the treatment of experimental Mycobacterium leprae infection of the mouse foot-pad was reported. In this study, $2 \mathrm{mg}$ of streptomycin injected subcutaneously 5 times weekly, continuously from the time of infection, prevented multiplication of $M$. leprae for the $15 \frac{1}{2}$-month study duration. In a later study $(1968)^{7} \mathrm{M}$. leprae-infected mice were treated by the 'kinetic method' with $2 \mathrm{mg}$ of streptomycin 3 times a week from day 30 to 86 following infection. The growth of M. leprae was found to be inhibited during the period of drug administration but resumed promptly when therapy was discontinued, suggesting that streptomycin was purely bacteriostatic. More

Present addresses:

* Seton Medical Center, 1900 Sullivan Avenue, Daly City, California 94015 (415/991-6652).

$\dagger 225$ Redding Avenue, Castro Valley, California 94546.

$\ddagger$ Department of Anatomy, Box 3011, Duke Univ. Med. Cen., Durham, North Carolina 27710. 
recently (1978), the activity of streptomycin against $M$. leprae-infected mice was studied.$^{6}$ It was found that $50-100 \mathrm{mg} / \mathrm{kg}$ was the minimal effective dose and that $100 \mathrm{mg} / \mathrm{kg}$ twice weekly to $M$. leprae-inf ected mice beginning 2 and 22 days after infection resulted in 93 and $81 \%$ killing respectively, as determined by the 'proportional bactericidal test'. ${ }^{10}$ The only study of the activity of other agents of this class in experimental leprosy so far was published in $1967 ; 5$ it found gentamicin 'partially' active in the treatment of $M$. leprae-infected mice by the subcutaneous route at a dose of $165 \mathrm{mg} / \mathrm{kg} 5-7$ times weekly continuously from the time of infection. Because of the paucity of information, particularly of a quantitative nature, concerning the activity of various aminoglycosides against $M$. leprae, we initiated this study to compare the killing potential of high-dose daily therapy with a number of these agents against $M$. leprae-infected mice.

\section{Materials and methods}

The methods used in this study to assess bactericidal activity are necessitated because $M$. leprae has not yet been successfully cultivated in artificial media or tissue culture. In this study we utilized the 'proportional bactericidal test', first used by Hilson \& Banerjee ${ }^{11}$ with Mycobacterium lepraemurium, as Colston et al. ${ }^{10}$ adapted it previously in order to assess the activity of ingested antimicrobials against $M$. leprae. Basically, this method involves inoculating groups of mice with serial dilutions of $M$. leprae in the foot-pads, treating the mice for a limited period, and then assessing bacillary growth after sufficient time has elapsed for detectable growth to have occurred from any surviving bacilli.

For the control and each treatment, 3 groups of 10 female BALB/c weanling mice were inoculated in both hind feet with $10^{1}, 10^{2}$ or $10^{3} \mathrm{M}$. leprae. Control mice were left untreated. Aminoglycosides were given as 60 daily (days 2-61) intraperitoneal injections in alternating sites, with each dose being given in $0 \cdot 2 \mathrm{ml}$ of sterile normal saline. Weekly average animal weights were used to maintain dosages at $150 \mathrm{mg}$ streptomycin/ $\mathrm{kg}$ (approximately $3.1 \mathrm{mg}$ ), $100 \mathrm{mg}$ kanamy$\mathrm{cin} / \mathrm{kg}, 100 \mathrm{mg}$ amikacin $/ \mathrm{kg}, 20 \mathrm{mg}$ tobramycin $/ \mathrm{kg}$ or $20 \mathrm{mg}$ gentamicin $/ \mathrm{kg}$. In addition, similar groups of mice were treated with $0.0001 \%$ dietary dapsone (the minimally effective dose ${ }^{12}$ ) or with a combination of $0.0001 \%$ dietary dapsone and daily streptomycin $(150 \mathrm{mg} / \mathrm{kg})$ injections. Generalized seizures immediately after drug administration, leading to death, occurred in up to $50 \%$ of the streptomycin and streptomycin + dapsone treated animals during the fifth week of therapy. This prompted discontinuation of streptomycin therapy in these groups on day 38.

One year after the completion of drug therapy, mice were killed and $M$. leprae were enumerated by standard techniques ${ }^{13}$ in each of 10 foot-pads from all but 2 groups of mice. $M$. leprae from only 8 foot-pads were counted in 1 streptomycintreated group because of early deaths, and $M$. leprae from only 8 foot-pads were 
counted in 1 amikacin-treated group because of random animal mortality throughout the study period. For purposes of calculation, growth of $M$. leprae was presumed to have occurred when foot-pad counts were $5 \times 10^{4}$. Percent decrease in the size of the $M$. leprae population ('killing') was calculated by a 'most probable number' calculation ${ }^{14}$ and the Spearman-Kärber calculation described by Shepard. ${ }^{15}$

\section{Results}

The foot-pad results and the resultant 'percent of bacteria killed' from this study are presented in Table 1 by means of both the most probable number and the

Table 1. Aminoglycoside antibiotics foot-pad results

\begin{tabular}{|c|c|c|c|c|c|}
\hline & \multirow{2}{*}{\multicolumn{3}{|c|}{ Positive/negative }} & \multicolumn{2}{|c|}{ Killed (\%) } \\
\hline & & & & Most probable & Spearman- \\
\hline & $10^{3}$ & $10^{2}$ & $10^{1}$ & No. technique & Kärber \\
\hline Control & —* & $10 / 0$ & $9 / 1$ & & \\
\hline Streptomycin & $10 / 0$ & $3 / 5$ & $0 / 10$ & $97 \cdot 2$ & $97 \pm 2$ \\
\hline Kanamycin & $2 / 8$ & $2 / 8$ & $0 / 10$ & $99 \cdot 8$ & $99 \cdot 7 \pm 0 \cdot 2$ \\
\hline Tobramycin & -* & $10 / 0$ & $7 / 3$ & $28 \cdot 7$ & $37 \pm 22$ \\
\hline Gentamicin & —* & $10 / 0$ & $5 / 5$ & $58 \cdot 5$ & $60 \pm 20$ \\
\hline Amikacin & $9 / 1$ & $6 / 4$ & $0 / 8$ & $97 \cdot 3$ & $96 \pm 3$ \\
\hline Dapsone & —* & - & $10 / 0$ & & \\
\hline Dapsone + streptomycin & $10 / 0$ & $5 / 5$ & $1 / 9$ & $95 \cdot 7$ & $95 \pm 2$ \\
\hline
\end{tabular}

* Not counted.

Spearman-Kärber calculation. There was remarkable concurrence in the results found by the 2 methods, the Spearman-Kärber calculation having the advantage of allowing the expression of confidence limits. Kanamycin apparently was the most active agent $(99 \cdot 7 \pm 0 \cdot 2 \%$ bactericidal), but both streptomycin and amikacin had impressive activity as well ( $97 \pm 2 \%$ and $96 \pm 3 \%$ bactericidal respectively). Gentamicin was minimally active $(60 \pm 20 \%)$, while tobramycin's activity $(37 \pm 22 \%)$ was not significantly different from controls $(P=0 \cdot 27)$. The slightly decreased activity with the addition of dapsone to streptomycin, when compared to streptomycin, is within the error limits of the experimental system $(P=0 \cdot 40)$.

Table 2 allows comparison of the killing potential towards $M$. leprae of the tested aminoglycosides in very high dosage with that of other agents previously studied $^{10}$ in dosages more nearly approximating those chronically tolerated in man. It is noteworthy that streptomycin, amikacin and kanamycin, in the high doses used in this study, are more active than certain of those drugs commonly used to treat leprosy patients, particularly dapsone. 
Table 2. Killing potential of various antibiotics by the proportional bactericidal test

\begin{tabular}{lc}
\hline \multicolumn{1}{c}{ Drug (dietary concentration) } & 'Killed' $(\%)$ \\
\hline Thiambutosine $(0 \cdot 1 \%)^{*}$ & 0 \\
Thiocarlide $(0 \cdot 1 \%)^{*}$ & 0 \\
Thiacetazone $(0 \cdot 1 \%)^{*}$ & 42 \\
Dapsone $(0 \cdot 01 \%)^{*}$ & 78,72 \\
Clofazimine $(0 \cdot 01 \%)^{*}$ & 98 \\
Clofazimine $(0 \cdot 003 \%)^{*}$ & 99,96 \\
Prothionamide $(0 \cdot 1 \%)^{*}$ & 98.6 \\
Ethionamide $(0 \cdot 1 \%)^{*}$ & $98 \cdot 6$ \\
Ethionamide $(0 \cdot 2 \%)^{*}$ & $97 \cdot 4$ \\
Rifampicin $(0 \cdot 003 \%)^{*}$ & 99.9 \\
Rifampicin $(0 \cdot 01 \%)^{*}$ & 100 \\
Streptomycin & $97 \cdot 2$ \\
Amikacin & $97 \cdot 3$ \\
Kanamycin & $99 \cdot 8$ \\
\end{tabular}

* Data from Colston et al. ${ }^{10}$

\section{Discussion}

This study has demonstrated the significant antimicrobial activity against $M$. leprae of very high doses of streptomycin, kanamycin and amikacin and the inactivity of gentamicin and tobramycin. Cultivable mycobacteria have been demonstrated to exhibit a similar pattern of aminoglycoside sensitivity, with kanamycin and especially amikacin being particularly effective. It has been found ${ }^{17}$ that amikacin at clinically achievable levels inhibited all 54 strains tested of $M$. fortuitum $(\mathrm{MIC}<2 \mu \mathrm{g} / \mathrm{ml})$ and all 11 strains of $M$. chelonei $(\mathrm{MIC}<16$ $\mu \mathrm{g} / \mathrm{ml})$. Though kanamycin inhibited all strains of $M$. fortuitum and $M$. chelonei at $16 \mu \mathrm{g} / \mathrm{ml}$, the median MIC to it was $8 \mu \mathrm{g} / \mathrm{ml}$ and $1 \mu \mathrm{g} / \mathrm{ml}$ for amikacin. However, as in our study, Wallace found gentamicin and tobramycin less active: only $28 \%$ of the $M$. fortuitum strains were inhibited by clinically achievable levels of gentamicin and tobramycin $(4 \mu \mathrm{g} / \mathrm{ml})$; all strains were resistant to streptomycin $(\mathrm{MIC}>32 \mu \mathrm{g} / \mathrm{ml})$. It was found ${ }^{17}$ that strains of $M$. fortuitum were universally susceptible to $<1 \mu \mathrm{g} / \mathrm{ml}$ amikacin, but that $M$. chelonei required as much as 32 $\mu \mathrm{g} / \mathrm{ml}$ for inhibition. In this study kanamycin was more active against $M$. chelonei and less active against $M$. fortuitum.

It has been found ${ }^{19}$ that all 33 tested strains of $M$. fortuitum and $M$. chelonei were inhibited by $2 \mu \mathrm{g} / \mathrm{ml}$ amikacin. Another study ${ }^{19}$ found that amikacin and kanamycin were active against the 10 tested strains of $M$. marinum and that gentamicin was inactive. It has been found ${ }^{20}$ that all isolates of $M$. marinum tested 
were sensitive to amikacin and kanamycin and resistant to gentamicin and tobramycin. It has also been found ${ }^{21}$ that amikacin was active against all 100 strains of a wide variety of atypical mycobacteria: 69 were sensitive to $1.6 \mu \mathrm{g} / \mathrm{ml}$, 30 required $3.2 \mu \mathrm{g} / \mathrm{ml}$ and 1 was only sensitive to $6 \cdot 7 \mu \mathrm{g} / \mathrm{ml}$.

Few published or pharmaceutical-company references exist for chronic administration of high doses of a minoglycosides to mice, and fewer for prolonged intraperitoneal injection of the agents (data from computer-assisted searches of literature and in-plant information, James T. Baldini, Schering Corporation, Harold W. Brinkley, Bristol Laboratories, Robert J. Petrick, Pfizer Laboratories, written communications; and Medline search). Because of this dearth of literature, dosage schedules generally had to be extrapolated from subcutaneous administration schedules in mice or rats and intraperitoneal injection data in rats. Despite the potential for neuromuscular blockade, nephrotoxicity and resultant death, mice treated with kanamycin, amikacin, tobramycin or gentamicin retained sufficient renal function to survive for the year after the protracted high-dose course of antibiotics. Mice treated with streptomycin fared well until the fifth week, when their therapy was prematurely halted because of seizurerelated deaths immediately after injection. All mice treated with streptomycin and surviving this therapeutic period had enough renal reserve to live until the completion of the study.

The practicality and usefulness of aminoglycosides in the treatment of human leprosy have not yet been established. A number of studies (judged by clinical criteria alone) have shown that streptomycin is active in human leprosy. ${ }^{1-4} \mathrm{~A}$ small pilot trial in previously untreated lepromatous leprosy patients in Malaysia, utilizing streptomycin intramuscularly in a daily dose of $0.75-1.5 \mathrm{~g}$, resulted in clinical improvement comparable to dapsone, a fall in the morphological index (percent of solid-staining bacilli in skin smears, generally correlating with viability) similar to that observed with dapsone and a loss of mouse foot-pad infectivity of skin biopsy specimens that was somewhat faster than with dapsone. ${ }^{9}$ Five of the ten dapsone-resistant patients treated with dapsone and streptomycin by Hastings et al..$^{22}$ relapsed clinically, and new lesions showed high morphological indices after only $23-31$ months of treatment with both drugs. Unfortunately, streptomycin resistance was not proved by mouse inoculation in these cases. No leprosy trials with other agents of this class have been published.

Aminoglycosides, as a class of antimicrobial agents, may have a place in the therapy of leprosy if pharmacological and toxic problems associated with their use can be circumvented. The potential for utilization of the aminoglycosides in treatment of infectious diseases, including leprosy, is limited by the necessity of their injection and by their pronounced oto- and nephrotoxicity in acute, subacute or chronic administrations. On the other hand, rifampin and streptomycin have been found to be truly synergistic against $M$. kansasii and $M$. intracellulare infections of mice. ${ }^{23}$ If such synergism was found for $M$. leprae, the discovery would certainly rekindle enthusiasm for a reconsideration of a clinical 
role for these agents. Pattyn et al. ${ }^{6}$ have found once weekly streptomycin to be equally effective in inhibiting growth of $M$. leprae in mice to twice and thrice weekly. As $\mathrm{WHO}^{24}$ has recommended intermittent supervised combination therapy, the use of aminoglycoside antibiotics might prove especially practical, if aminoglycoside therapy could be correspondingly spaced out to monthly intervals. Experiments are currently in progress in mice to assess the combined activity of certain of these active aminoglycosides with rifampin and the efficacy of decreasing the dose and frequency of aminoglycoside administration.

\section{References}

1 Doull JA. Clinical evaluation studies in lepromatous leprosy; first series: diasone (diamidin), 4,4'-diaminodiphenylsulfone and dihydrostreptomycin. Int J Lepr, 1954; 22: 377-402.

2 Doull JA, Wolcott RR. Medical Progress: Treatment of leprosy; chemotherapy. N Engl J Med, 1956; 254: 20-5.

3 Driesbach J, Cochrane RG. A study of the effect of streptohydrazid on lepromatous leprosy over a period of about three years. Le pr Rev, 1958; 29: 136-42.

${ }^{4}$ Faget GHA, Erickson PT. Use of streptomycin in the treatment of leprosy; preliminary report. Int J Lepr, 1947; 15: 146-53.

5 Gaugas JM. Antimicrobial therapy of experimental human leprosy (Myco. leprae) infection in the mouse foot pad. Lepr Rev, 1967; 38: 225-30.

${ }^{6}$ Pattyn SR, Saerens E. Evaluation of the activity of streptomycin on Mycobacterium leprae in mice. Lepr Rev, 1978; 49: 275-81.

7 Shepard CC. A kinetic method for the study of activity of drugs against Mycobacterium leprae in mice. Int J Lepr, 1967; 35: 429-35.

${ }^{8}$ Shepard CC, Chang YT. Activity of antituberculosis drugs against Mycobacterium leprae: studies with experimental infection of mouse footpads. Int J Lepr, 1964; 32: 260-71.

9 Waters MFR, Gelber RH. U.S.-Japan Cooperative Medical Science Program. Workshop on Chemotherapy. Int J Lepr, 1976; 44: 369-73.

10 Colston MJ, Hilson GRF, Banerjee DK. The 'proportional bactericidal test': A method for assessing bactericidal activity of drugs against Mycobacterium leprae in mice. Lepr Rev, 1978; 49: 7-15.

11 Hilson GRF, Banerjee DK. The proportional bactericidal test: A method for testing in-vivo bactericidal action of a persisting drug. Int Res Commun Sys (Med Sci), 1974; 2: 1037.

12 Shepard CC, Levy L, Fasal P. The sensitivity to dapsone (DDS) of Mycobacterium leprae from patients with and without previous treatment. Am J Trop Med Hyg, 1969; 18: 258-63.

13 Shepard CC. The experimental disease that follows the injection of human leprosy bacilli into foot-pads of mice. J Exper Med, 1960; 112: 445-54.

14 Taylor J. The estimation of numbers of bacteria by tenfold dilution series. J Appl Bact, 1962; 25: 54-61.

15 Shepard CC. Statistical analysis of results obtained by two methods for testing drug activity against Mycobacterium leprae. Int J Le pr, 1982; 96-101.

16 Wallace RJ, Dalovisio JD, Pankey GA. Disk diffusion susceptibility of Mycobacterium fortuitum and Mycobacterium chelonii to antibacterial agents. Antimicrob Agents \& Chemother, 1979; 16: 611-14.

17 Welch DF, Kelley MT. Antimicrobial susceptibility testing of Myco. fortuitum in mice. Antimicrob Agents \& Chemother, 1978; 15: 754-7. 
18 Dalovisio JR, Pankey GA. In vitro susceptibility of $M$. fortuitum and $M$. chelonii to amikacin. $J$ Infec Dis, 1978; 137: 318-21.

19 Sanders WJ, Wolinsky E. In vitro susceptibility of $M$. marinum to 8 antimicrobial agents. Antimicrob Agents \& Chemother, 1980; 18: 529.

${ }^{20}$ Wallace RJ, Wiss K. Susceptibility of $M$. marinum to tetracyclines and aminoglycosides. Antimicrob Agents \& Chemother, 1981; 20: 610-12.

${ }^{21}$ Gangadharam PRJ, Chandler ER. In vitro anti-mycobacterial activity of some new aminoglycoside antibiotics. Tubercle, 1977; 58: 35-8.

${ }^{22}$ Hastings RC, Trautman JR, Mansfield RE. Further observations on streptomycin combined with sulfones in relapsed lepromatous leprosy. Int J Lepr, 1969; 37: 130-4.

${ }^{23}$ Shronts JS, Rynearson TK, Wolinsky E. Rifampin alone and combined with other drugs in Mycobacterium kansasii and Mycobacterium intracellulare infections of mice. Am Rev Resp Dis, 1971; 104: 728-41.

${ }^{24}$ Chemotherapy of leprosy for control programmes. Technical Report Series 675. WHO, Geneva, 1982. 